\title{
Review Article \\ Review of Sensing Methodologies for Estimation of Combustion Metrics
}

\author{
Libin Jia, Jeffrey D. Naber, and Jason R. Blough \\ Michigan Technological University, 1400 Townsend Drive, Houghton, MI 49931, USA \\ Correspondence should be addressed to Libin Jia; libinj@mtu.edu
}

Received 3 July 2015; Accepted 10 January 2016

Academic Editor: Sergey M. Frolov

Copyright (C) 2016 Libin Jia et al. This is an open access article distributed under the Creative Commons Attribution License, which permits unrestricted use, distribution, and reproduction in any medium, provided the original work is properly cited.

For reduction of engine-out emissions and improvement of fuel economy, closed-loop control of the combustion process has been explored and documented by many researchers. In the closed-loop control, the engine control parameters are optimized according to the estimated instantaneous combustion metrics provided by the combustion sensing process. Combustion sensing process is primarily composed of two aspects: combustion response signal acquisition and response signal processing. As a number of different signals have been employed as the response signal and the signal processing techniques can be different, this paper did a review work concerning the two aspects: combustion response signals and signal processing techniques. In-cylinder pressure signal was not investigated as one of the response signals in this paper since it has been studied and documented in many publications and also due to its high cost and inconvenience in the application.

\section{Introduction}

Determination of combustion metrics for an internal combustion engine has the potential of providing feedback for closed-loop combustion phasing control to meet current and upcoming emission and fuel consumption regulations. Closed-loop control of the combustion process has been a focus for engine research and development [1-3]. Open-loop operation based on calibration maps which are conservatively set based upon laboratory operation can give a quick response and is relatively easy to control. However, the open loop cannot adapt to the changes caused by the condition variations such as injector aging and fuel quality [2].

In comparison, closed-loop control considers the condition changes in the control mechanism and enables operation closer to the optimum fuel consumption and emissions target. Combustion metrics detected or estimated through a sensor, which is referred to as combustion sensing output, provides feedback information to control the combustion process. In this paper, the combustion metrics being addressed involves SOC (start of combustion), peak pressure location, peak apparent heat release rate location, CA50 (crank-angle location for 50\% fuel burnt), and so forth. The feedback information provided by the combustion sensing process also refers to the abnormal combustion phenomena including knock and misfire events. In this paper, a review was performed for combustion sensing methodologies concerning combustion metrics estimation with respect to combustion sensing response signals and signal processing techniques.

\section{Response Signal for Combustion Event}

In-cylinder pressure waveform is the most commonly used signal which provides the information for engine combustion control [4-6]. In-cylinder pressure signal has been historically used in the laboratory and more recently in series production to derive the combustion metrics and provide feedback for combustion phasing control [7-9]. However, the measurement of the in-cylinder pressure is typically obtained with intrusive sensors that require a special mounting process and engine structure modification. Also the in-cylinder pressure transducer has a high cost for mass production for diesel engines [10]. So the response signals discussed in this paper do not include the in-cylinder pressure signal.

2.1. Crank-Shaft Speed Fluctuation. Due to the variations of the in-cylinder pressure waveform during a combustion 
cycle, the crank-shaft speed fluctuation varies in a complex way which depends on the engine parameters. How the speed fluctuation varies with the engine in-cylinder pressure changes has been explored by many researchers so as to develop a good alternative to the direct intrusive in-cylinder pressure measurement [11-19].

Based on a model that relates the crank-shaft speed and the in-cylinder pressure, the in-cylinder pressure can be estimated with the input of instantaneous speed signal measured by a crank-shaft speed sensor. The sensor can be an optical encoder or a magnetic pickup transducer which are easy to mount and low in cost.

Moro et al. [11] proposed a linear dependency between the in-cylinder pressure and the engine speed signal and experimentally verified it for 38 different engine running conditions. The equation that can represent this linear dependency is given as [11]

$$
\begin{aligned}
\operatorname{Ar} & \left(p(t)-p_{\text {misf }}(t)\right) f_{\text {crank }}=J \ddot{\theta}_{s}(t)-\ddot{\theta}_{s \text { misf }}(t) \\
& =J \Delta \ddot{\theta}_{s}(t),
\end{aligned}
$$

where $A$ is piston area in $\mathrm{m}^{2}, r$ is the crank radius in $\mathrm{m}, p_{\text {misf }}$ is the in-cylinder pressure in case of misfire (bar), $\ddot{\theta}_{s}$ is the synthetic engine acceleration in $\mathrm{rad} / \mathrm{s}^{2}, \ddot{\theta}_{s \text { misf }}$ is the synthetic engine acceleration in case of misfire $\mathrm{rad} / \mathrm{s}^{2}, J$ is the moment of initial $\left(\mathrm{kg} \cdot \mathrm{m}^{2}\right)$, and $f_{\text {crank }}$ is the crank-slider kinematics function.

A frequency response function between the in-cylinder pressure and the engine speed can be obtained by converting (1) into frequency domain. However, this FRF is sensitive to engine running conditions and the FRF obtained based on one condition does not lead to the estimated in-cylinder pressure with high accuracy when condition varies. So a FRF mapping was created in this paper based on 38 different steady-state engine conditions with the engine speed and the manifold pressure as the condition parameters to distinguish different test conditions. For the conditions falling into the FRF mapping, interpolation technique was used for both real and imaginary harmonic components to obtain the estimated FRF. The pressure recovery results for low speed low load, high speed low load, and low speed high load conditions were shown in this paper.

Connolly and Yagle modeled the cylinder combustion pressure via the crank-shaft velocity from a statistical point of view [12]. The model involves three sequent components. First, by replacing the time domain independent variables with crank-angle variables, a nonlinear differential model between the crank's shaft speed and the in-cylinder pressure signal can be simplified. Secondly, the in-cylinder pressure signal was parameterized by the sample modeling sequence based on a stochastic model which uses the sum of the deterministic waveform and an amplitude-modulated cosine window. Third, an estimation of the in-cylinder pressure based on the crank-shaft speed signal was achieved through a state-space deconvolution process which utilized a Kalman filter. Moreover, signal to noise ratio effects to the in-cylinder pressure estimation were also evaluated in this paper. Results showed that for low to moderate noise level conditions the reasonable deconvolution can be reached.

Shiao and Moskwa [13] employed a sliding observer to estimate the in-cylinder pressure and combustion heat release for an SI engine. To estimate the in-cylinder pressure with high accuracy, the error between the measured and the estimated crank-shaft speed was taken as the feedback to reduce the dynamic error of the estimated in-cylinder pressure. The unobservability problem arises for the pressure estimation around the top-dead center and thus introduces significant estimation error. This problem was partly solved by adapting the parameters of the observer. Then the estimated incylinder pressure was used to compute the cylinder heat release. Also, detection of misfire or abnormal combustion events was achieved through the estimated heat release.

Additional investigators examining combustion metrics analysis based on the crank-shaft speed fluctuation can be found in [14-16]. In addition to estimating the in-cylinder pressure waveform and the heat release, engine crank-shaft speed was also used to recover the engine torque [17-19]. For most cases, the crank-shaft speed was fed into an engine model which was simplified based on assumptions to estimate the engine torque.

2.2. In-Cylinder Ion Current. Ion current in the combustion chamber is measured via the spark plug. After the highvoltage discharge, the ion current across the spark plug gap is obtained by applying a DC voltage across the gap and measuring the resulting current. The ion current is affected by gas flow, geometry of flame, electric potential, ion density, and the angle between the flame and electrode [20]. The ionization of gases in the cylinder occurs in two phases. When the fuel reacts with the oxygen during combustion, the first phase ionization occurs which can be considered as chemical phase. The second phase, defined as thermal phase, occurs when the burnt gases are compressed by the increased in-cylinder pressure [21]. The most consistent dependency between the ion current and in-cylinder pressure occurs on the peaks of the two signals for both amplitude and the location perspectives. This has been verified by the researches in [20-25].

Martychenko et al. [22] detected the breakdown voltage across the spark plug gap and modeled the relationship between the peak of the voltage and the peak of the in-cylinder pressure based on second-order polynomial function. The coefficients of the second-order polynomial function for the conditions with varied engine speed are different. However, the coefficients can be curve-fitted by a linear function of engine speeds. Hellring and Holmberg [21] proposed least squares fit method to estimate the in-cylinder pressure peak position of spark ignited engines based on the ion current signal. This method was proved to have a better robustness and accuracy than multilayer perceptron and Gaussian curve fit methods for peak in-cylinder pressure estimation.

Gazis et al. [28] explored the possibility of estimating in-cylinder characteristics based on the ion current with one simple and computationally inexpensive neural network, adaptive linear type of network. Thirteen extracted 
characteristics of the ion current were taken as the input and four characteristics of the in-cylinder pressure (peak pressure position, peak pressure magnitude, the width of curve at half of its height, and the area of the curve between inlet valve closing (IVC) and exhaust valve opening (EVO)) as the output to train the network with the purpose of predicting the four characteristics of in-cylinder pressure. Also, based on the same neural network structure but with the whole ion current signal (time domain sampled between IVC and EVO) as the input and the whole in-cylinder pressure signal (time synced with ion current signal) as the output, the in-cylinder pressure curve rather than just some characteristics of the incylinder pressure signal can be estimated. The peak pressure location, as one of the most important in-cylinder pressure characteristics, was predicted with the mean error at 0.062 degrees and standard deviation at 2.55 degrees.

Ion current was also used to detect engine knock, misfire, or incomplete combustion [24, 29-31]. Kumar et al. [24] applied a band-pass filter on the ion current signal and the filtered output indicates the engine knock. Danne et al. [29] compared the ion current based knock detection with the conventional methods of pressure based and accelerometerbased knock detection on a large-displacement, air-cooled, V-twin motorcycle engine. It was found that the ion current based method can detect the inaudible knock more accurately and reject the mechanical noise more effectively than the other two conventional methods. Zhu et al. [30] found that the in-cylinder ion current can detect misfire or incomplete combustion. Also, the ion current signal can be used to compute minimum spark advance for best torque (MBT) to measure the combustion stability [30,32]. However, the results are only limited to a fixed load over a narrow speed range.

2.3. Accelerometer Signal. Accelerometers are mounted externally on the engine block or the engine head to detect the combustion events by measuring the vibration signals which are transmitted from the in-cylinder oscillation to the engine outer surface. However, as the accelerometer detects the vibrations from the sources in addition to the cylinder oscillation including the valve dynamics and piston slaps, the signal may vary from cylinder to cylinder and over operating conditions. So the utilization of the accelerometer signal for combustion metrics detection relies on the signal processing technique which can eliminate the effects from other sources.

Naber et al. [33] evaluated the effectiveness and accuracy of accelerometer-based knock detection. The distributions of the accelerometer-based knock intensity metrics for various operation conditions including varied speeds, loads, cam timings, and knock levels were measured and fitted by a log-norm distribution. The log-norm model was verified to provide a good fit of the distributions and the distribution characteristics including skewness and peakedness. In addition, a good correlation can be seen between the cylinder pressure based knock intensity metrics and the accelerometer-based knock intensity metrics. Guillemin et al. [34] estimated the instantaneous engine knock by fitting the accelerometer signals with Gaussian function on a $2.2 \mathrm{~L} \mathrm{HCCI}$ engine and measure the start of combustion where the knock level is out of the user-defined threshold.

Characteristics of the accelerometer signal which are related to the characteristics of in-cylinder pressure or apparent heat release rate were investigated and extracted [35-37]. Some characteristics of the in-cylinder pressure or apparent heat release including start of combustion, CA50, and peak pressure crank-angle location are closely related to the combustion process and thus can be used as the feedback to control the combustion process. Arnone et al. [35] band-pass filtered the in-cylinder pressure signal and the accelerometer signal within $650-1000 \mathrm{~Hz}$ and found that the accelerometer signal can locate the sudden rise of the in-cylinder pressure signal (so as to denote the start of combustion), diffusive combustion process, and the peak of the in-cylinder pressure on a water cooled Lombardini LDW442CRS direct injection common rail diesel engine. Chiavola et al. [36] computed the cumulative heat release based on the measured incylinder pressure and investigated the relationship between the accelerometer signal and the cumulative heat release on a two-cylinder diesel engine equipped with a common rail injection system. By superimposing the filtered accelerometer signal to the cumulative heat release, it was found that the filtered accelerometer signal can locate the start of combustion, the beginning of main combustion, and MFB50 (50\% of the burnt fuel mass). Taglialatela et al. [37] investigated the correlation between the in-cylinder pressure signal and the features derived from the accelerometer signal on a $4 \mathrm{~L}$ single cylinder SI engine. Time-frequency spectrogram method was utilized to analyze the accelerometer signal to present more features of the accelerometer signal than the analysis in time domain. The result indicates a direct correlation between the peak pressure location and the maximum amplitude of accelerometer signal in time-frequency domain for all the engine operating conditions conducted in this paper. So the maximum amplitude location of the accelerometer signal can be used as the feedback for a closed-loop control system of spark advance.

Polonowski et al. [38] explored the potential of accelerometers to recover the in-cylinder pressure curve on a $1.9 \mathrm{~L}$ four-cylinder, turbocharged, HPCR, direct injection diesel engine. In this paper, standard signal processing techniques including Fast Fourier Transform (FFT) and coherence were employed and results showed that a strong coherence presented between the in-cylinder pressure signal and the accelerometer signal within frequency band of $0.5 \mathrm{kHz}$ to $4 \mathrm{kHz}$ with the coherence value over 0.9. Also, this research found that the accelerometer location did result in a varied coherence value between the in-cylinder pressure signal and the accelerometer signal. The optimal locations for the accelerometer placement were determined based on both offline and online coherence analysis. In his later work [39], frequency response function (FRF) was used to quantify the relationship between accelerometer response and AHR and the relationship between accelerometer response and in-cylinder pressure. A technique termed as spectrum weighting was utilized to combine FRFs from all conducted test conditions into a single FRF by weighting the 
FRF magnitude and phase information for each frequency by the coherent output power at that specific frequency.

This obtained FRF was used to estimate in-cylinder pressure and AHR on a cycle-cycle basis. The maximum pressure gradient determination was shown to have a root mean square error (RMSE) accuracy of $15 \%$ of actual maximum pressure gradient. The location based metrics had the RMSE as small as $0.29^{\circ}$ and more than $80 \%$ of the estimated peak apparent heat locations were within $1^{\circ}$ crank-angle.

\section{Signal Processing Techniques to Correlate the Combustion Metrics and the Response Signal}

3.1. Frequency Response Function (FRF). The pressure curve recovery depends on the transfer path modeling between the acquired source signal (in-cylinder pressure signal) and the response signal (e.g., vibration signal). Frequency response function which represents the frequency domain relationship between the in-cylinder pressure signal, $P(\omega)$, and the accelerometer signal, $A(\omega)$, can be presented by

$$
A(\omega)=P(\omega) H(\omega) .
$$

$H(\omega)$ is the transfer path in frequency domain and is defined as the frequency response function (FRF). With the FRF obtained by measuring both $P(\omega)$ and $A(\omega)$ based on the representative operating conditions, the in-cylinder pressure signal of any other condition can be recovered with the measured $A(\omega)$ and the obtained $H(\omega)$ by

$$
P(\omega)=A(\omega) H^{-1}(\omega) .
$$

However, as the response signal is sensitive to not only the incylinder pressure oscillation but the rotating crank-slider and vibration from other mechanical parts including piston slaps and valve dynamics which varies with the engine operating conditions, the FRF with assumption of linear dependency in frequency domain between the source signal and the response signal does not have a good robustness over engine operating conditions. This conclusion has been confirmed by researchers [39-42]. Gao and Randall [40] applied the FRF computed from $2400 \mathrm{rpm}$ full load condition to reconstruct the in-cylinder pressure with the accelerometer signal measured at $3600 \mathrm{rpm}$ and full load condition as the input. The significant recovery error for the in-cylinder pressure waveform indicated that the transfer path modeled by FRF cannot be considered consistent over engine operating conditions. Morello et al. [41] attempted to overcome the drawback of FRF application for the heat release recovery based on the accelerometer signal by optimizing the time domain window applied to the accelerometer signal. Also, a Vold-Kalman order tracking filter was employed to eliminate the abnormal harmonics of the singular value decomposition results of both the accelerometer signal and in-cylinder pressure signal. However, no significant heat release estimation accuracy improvement can be seen for start of injection (SOI) sweep test conditions. Polonowski [39] also tried to improve the FRF performance by adding a weighting function to the FRF. However, the robustness improvement for FRF is still limited.
Gao and Randall [40] explained why the variation of the FRF results in an error of source estimation with the Laplace transform. It can be seen that the variation of FRF introduces incomplete cancellation of the poles and zeros in the dominator with the accelerometer signal as the numerator. The incomplete cancellation of non-minimumphase zeros will make the extra poles or zeros of FRF present and make the inverse filtering unstable. As a result errors will be introduced to the estimation result.

3.2. Cepstrum Analysis. Complex cepstral analysis is a nonlinear homomorphic signal process which is being utilized in many areas including machine diagnostics, image processing, speech, and radar signal processing. A cepstrum is reached by taking the inverse Fourier transform of the logarithm of a signal spectrum. The complex cepstrum $X_{c}(t)$ can be expressed as

$$
X_{c}(t)=F^{-1}\{\log (F\{x(t)\})\} .
$$

$x(t)$ is the signal in time domain, $F$ represents the Fourier transform algorithm, and $F^{-1}$ denotes inverse Fourier transform.

Equation (5) can be obtained by applying logarithm to (2):

$$
\log (A)=\log (P)+\log (H) .
$$

After computing the inverses Fourier transform

$$
F^{-1}(\log (A))=F^{-1}(\log (P))+F^{-1}(\log (H)) .
$$

According to (4), the cepstrum of FRF can be obtained as

$$
H_{c}(t)=A_{c}(t)-P_{c}(t) .
$$

The advantage of this method is that the convolution process is converted to an addition process in cepstrum domain. ElGhamry et al. [42] applied the complex cepstrum analysis on the root mean square acoustic emission signal. The complex cepstrum of FRF, $H_{c}(t)$, was evaluated for four complete combustion cycles at $1280 \mathrm{rpm} 30 \mathrm{Nm}$ condition. By inserting $H_{c}(t)$ and $A_{c}(t)$ into (7), the cylinder pressure signal can be identified as

$$
P_{c}(t)=A_{c}(t)-H_{c}(t) .
$$

However, this method only gave good estimation of the in-cylinder pressure signal for the same engine operating conditions based on which $H_{c}(t)$ was computed.

Another important application of complex cepstral analysis is for signal smoothing. The complex cepstrum was utilized to improve the robustness of the transfer path by smoothing both the source signal and the response signal [34, $40,43]$. Smoothing the FRF actually reduces the variations of the FRF associated with different operating conditions. The schematic illustration for smoothing the FRF is shown in Figure 1.

In the process described in Figure 1, the smoothing of magnitude and phase was realized by applying a lowpass filter in quefrency domain to lifter the corresponding 


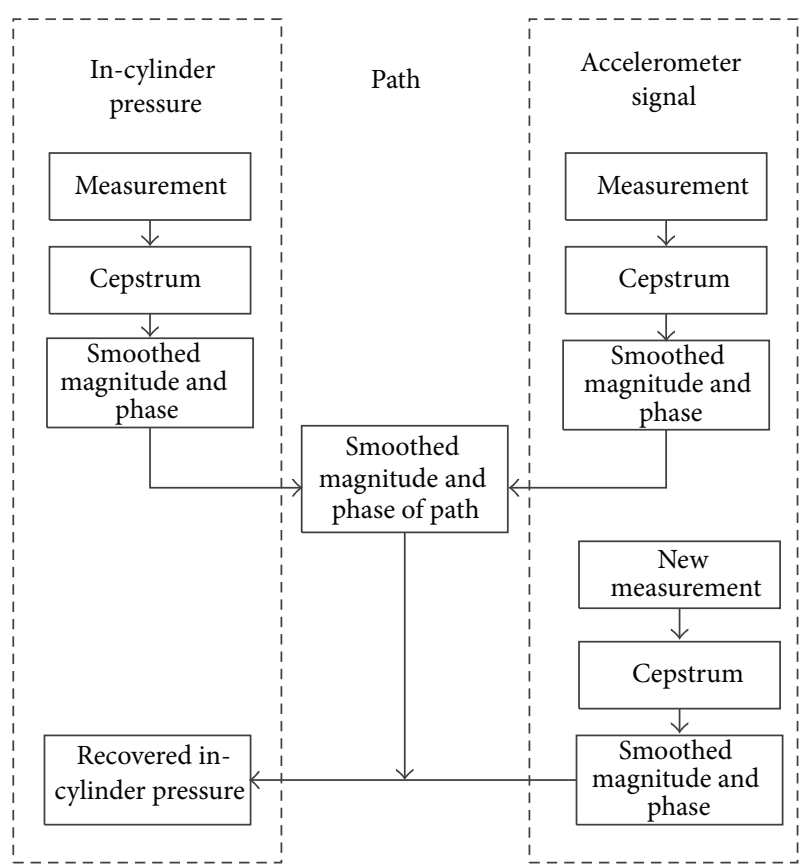

FIGURE 1: In-cylinder pressure estimation based on the cepstral smoothing technique.

content of complex cepstrum. In other words, the liftering process was achieved by applying a window around zero quefrency. Kim and Lyon [43] also discussed the effects of the window length in the signal smoothing and results showed that the shorter the window, the smoother the log spectrum. The smoothed amplitude and phase of FRF were obtained through (7) by smoothing the phase and amplitude of both the accelerometer signal and the premeasured incylinder pressure under the given conditions. By inserting the smoothed FRF into (8), the in-cylinder pressure signal was recovered by inputting the smoothed accelerometer signal measured from the same conditions on another engine structure of the same type.

Gao and Randall [40] applied the complex cepstral smoothing technique to obtain a smoothed FRF for incylinder pressure recovery. They compared the results based on four different in-cylinder pressure recovery methods, including two inverse filtering procedures (see (3) and (8)), the cepstral smoothed FRF, and the time domain smoothed FRF. It showed that the pressure waveforms recovered from the two smoothing operations can better match the measured ones than the pressure waveforms recovered from the two inverse filtering operations.

3.3. System Identification. FRF method assumed a linear dependency in frequency domain between the in-cylinder pressure and the vibration signal. However, the low robustness of the FRF with respect to the engine operating condition variations proved that the linear dependency needs to be adapted. System identification approach modeled the transfer path between the in-cylinder pressure and the accelerometer signal with a nonlinear hypothesis. Villarino and Böhme [44] modeled the transfer path as a filter which was applied to the in-cylinder pressure signal to output the accelerometer signal. Also, it was assumed that the accelerometer signal consists of a superposition of $K$ components with each component for one cylinder. The model was expressed as

$$
a_{n}=\left(1-B\left(q^{-1}\right)\right) a_{n}+\sum_{k=1}^{K} H_{k}\left(q^{-1}, n\right) p_{k, n}+\omega_{n} .
$$

$a_{n}$ as the measured accelerometer signal is the sum of the in-cylinder pressure $p_{n}$ filtered by a time-variant filter $H_{k}\left(q^{-1}, n\right)$, past accelerometer samples termed by $B\left(q^{-1}\right)=$ $1+\sum_{m=1}^{M} a_{m} q^{-m}$, and the noise termed by $\omega_{n} \cdot q^{-1}$ is the left shift operator and works as $q^{-m} a_{n}=a_{n-m}$.

The optimal filter coefficients $\widehat{B}(\cdot)$ and $\widehat{H}_{k}(\cdot)$ were estimated by minimizing the error $\epsilon_{n}$ between the estimated incylinder accelerometer signal $\hat{a}_{n}$ and the measured one $a_{n}$ :

$$
\left[\widehat{B}, \widehat{H}_{1}, \ldots, \widehat{H}_{k}\right]=\operatorname{argmin}\left(\sum_{n=1}^{N} \epsilon_{n}^{2}\right) .
$$

For the ease of reconstruction of the in-cylinder pressure, in-cylinder pressure trace was decomposed into three parts which are associated with the same dependent parameters. Expectation maximization algorithm was employed to recover the dependent parameters. The results showed that the peak pressure location estimation yields a mean error of $0.04^{\circ}$ with the standard deviation at $4.78^{\circ}$. However, the high estimation accuracy was limited to the same engine operating conditions. No results were reported when this method was applied to a varied engine operating condition.

Wagner et al. [45] built a physical model which denoted the speed dependence of the transfer path between the incylinder pressure and the accelerometer signal. SGN algorithm was used to identify the parameters of the transfer function speed-independently. Each pressure in this paper was considered to be composed of two parts with the first one introduced by the compression due to the piston movement and the second one generated by the pressure rise due to the combustion event. As the parameters were identified speedindependently, only one set of transfer path parameters needs to be stored for the in-cylinder pressure estimation.

Other than recovering the in-cylinder pressure signal, system identification approach was also used for misfire detection [46-48]. A function was developed to interpret the ratio between the energy of the signal and the energy of the noise, termed as signal energy-to-noise ratio in Villarino's work. A higher load can cause the signal energy-to-noise ratio to increase. A threshold value was determined with the function value lower than the threshold value indicating the occurrence of the misfire.

3.4. Neural Network. The modeled transfer paths described in the previous sections only work for limited engine operating conditions. The transfer behavior between the accelerometer and the combustion metrics (with the in-cylinder pressure as the example) is a nonlinear dynamic path highly depending on the input and the engine operating condition. For this reason, another nonlinear modeling approach, neural network, was employed to investigate the relationship 
between the combustion metrics and the response signal, including crank speed fluctuation $[12,15]$, the vibration signal $[49,50]$, and hybrid of crank speed fluctuation and vibration signal [26].

$\mathrm{Gu}$ et al. [15] modeled the relationship between the cranks shaft speed and the in-cylinder pressure with a radial basis function (RBF) neural network on a four-cylinder DI diesel engine. With network trained with the selected data, the incylinder pressure can be expressed as

$$
y_{k j}(\theta)=\sum_{m=1}^{M} h_{k m}(\theta) w_{m j},
$$

where $h_{k m}(\cdot)$ is the radial basis function and $w_{m j}$ are the weighting vectors. The RBF is composed of a linear layer represented by (11) and a nonlinear layer with radial basis functions as the components. The radial basis function is expressed as

$$
h_{k m}=\exp \left(-\frac{\left\|x_{k}-c_{m}\right\|}{r_{m}}\right),
$$

where $c_{m}$ is the hidden unit center, $x_{k}$ represents the crank speed input, and $r_{m}$ is the radius of the Gaussian function. $\|\cdot\|$ represents the Euclidean distance between the vectors. Results showed that the recovered pressure waveform matches well with the measured one for nine engine conditions with varied engine speeds and loads for all the phases: compression, peak pressure, and rise and fall of the combustion. Indicated mean effective pressure (IMEP) was also computed based on the recovered in-cylinder pressure signal and the IMEP from the recovered in-cylinder pressure can follow the respective measured values closely.

Taglialatela et al. [10] utilized the multilayer perceptron neural network to model the relationship between the crankshaft speed and parameters extracted from the in-cylinder pressure, including peak pressure value and peak pressure angular location, instead of the pressure waveform. With the trained neural network, the peak pressure amplitude can be estimated with minimum error of 2.31 bar and maximum error of 6.97 bar which are $4.1 \%$ and $8.0 \%$, respectively, in relative percentage scale. The peak pressure location can be estimated with minimum error of 1.38 crank-angle degrees and maximum of 5.20 crank-angle degrees.

Bizon et al. [49] reconstructed the in-cylinder pressure signal on a single cylinder $0.5 \mathrm{~L}$ diesel engine with the engine block vibration as the input signal to a trained RBF neural network. This paper focused on the RBF neural network parameters optimization with respect to the number of neurons and the spread parameter. 50 centers and spread parameter of 3.2 were finally determined and the RBF network structured with the optimized parameters was evaluated based on the peak pressure amplitude, peak pressure location, and the MBF50 which are derived from the recovered incylinder pressure. The peak pressure value estimation error was under $3 \%$ in relative RMSE and the peak location and MBF50 were both below 1.5 crank-angle degrees.

Johnsson [26] also employed the RBF neural network for the in-cylinder pressure recovery but with the hybrid of

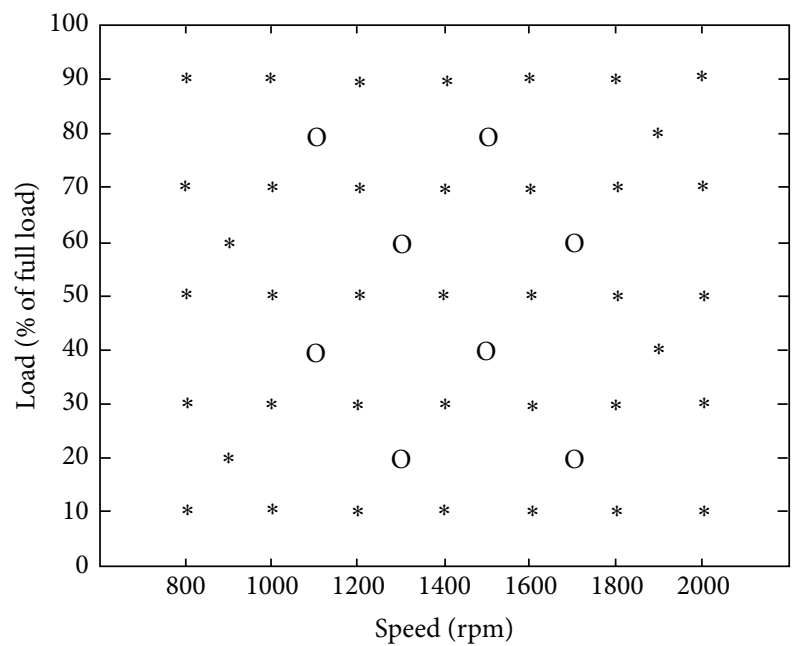

FIGURE 2: Engine operating conditions (o: validation data; $*$ : training data) [26].

vibration signal and the crank-shaft speed as the input on a 9litre, 6-cylinder, and inline four-stroke diesel engine. Because the coherence analysis indicated that the crank-shaft angular speed has the highest coherence with the in-cylinder pressure for the lowest frequency while the vibration signal has the highest coherence with the in-cylinder pressure for higher frequency, a recursive hybrid learning procedure was applied to train the neural network. K-means clustering algorithm found the $k$ centers and used the regularization to determine the weights. Fourier transform of vibration signal and the crank-shaft signal are taken as the input to the RBF neural network, so both the input and output are complex values. The training data and the validation data are presented in Figure 2.

The results showed that the RMS error of maximum pressure based on the validation data was 3.5 bar, the location for the maximum pressure was 1.5 degrees, and RMS error for IMEP was 0.7 bar.

3.5. Wavelet Method. Although the frequency domain signal processing techniques including the Fourier transform and the FRF have advantages in analyzing the raw signal and building the transfer path, the Fourier transform result is inefficient for nonstationary problems such as the engine vibration signal with the nonstationary effects introduced by the combustion events [51].

Also, the Fourier-transform-based technique is not capable of detecting the temporal variations of the periodicities due to its pure frequency domain dependency [52]. Wavelet transform as a popular time-frequency transform decomposes the signal into different frequency bands and allows the feature analysis associated with these frequency bands. This property makes wavelet transform a useful tool to analyze the signals with time discontinuities and sharp spikes, such as the vibration signal or the radiated sound of an engine during combustion.

Kim and Min [27] applied the Meyer wavelet transform to the engine block vibration signal obtained on a controlled 


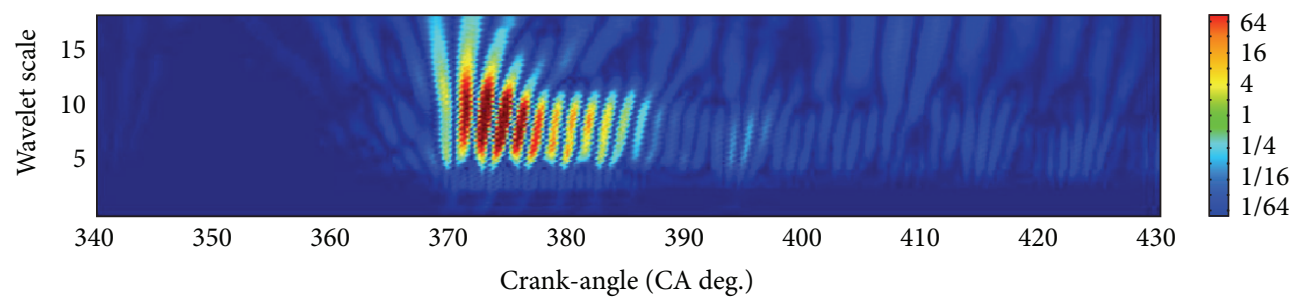

FIGURE 3: Wavelet transform result in a specific cycle for $1500 \mathrm{rpm}$ [27].

autoignition engine to detect the start of combustion which was defined as $2 \%$ mass fraction burned. The engine block vibration signal within $500 \mathrm{~Hz}$ to $7 \mathrm{kHz}$ was converted into wavelet scale with an interval of $100 \mathrm{~Hz}$. A threshold value was determined to correspond to the start of combustion and the wavelet scale which grows greater than this threshold value was used to locate the start of combustion for each frequency band. Then the averaged start of combustion for each frequency band was the final determined result. Figure 3 indicates the engine block vibration wavelet transform results and the start of combustion was determined at 363 crankangle degrees (3 degrees after top-dead center).

Hariyanto et al. [53] defined the pressure based start of combustion based on derivatives of the pressure trace and took it as reference. The technique for the start of combustion determination based on the vibration signal wavelet analysis used the trial and error method. Results showed that the averaged difference of the start of combustion between the two determination methods is below 1 crank-angle degree. The correlation coefficient of the start of combustion derived from in-cylinder pressure and the accelerometer signal is higher than 0.95 .

As the wavelet transform presents more details about the signal in time-frequency domain, features extraction can be achieved based on the wavelet transform analysis. Then the correlation between the features extracted from the vibration or sound signal and the features extracted from the in-cylinder pressure trace was investigated. However, no transfer path based on the wavelet transform has been developed and applied for the pressure waveform recovery. More researches concerning application of wavelet transform for engine combustion or engine radiated noise can be found in $[51,52,54]$.

\section{Summary}

Among the forementioned three signals for combustion metrics estimation or correlation, accelerometer signal was most utilized because the accelerometer has the advantage of low price and easy mounting as well as high reliability and durability. Also, utilization of multiple accelerometers which are placed at multiple locations on engine block can supply more than one input channel which have the potential of improving the combustion metrics estimation accuracy with the assistance of signal processing [55]. The limitation of usage of crank-shaft signal is that the instantaneous output torque near TDC where CI engine combustion typically starts is zero [56]. Also, the dynamics of the system limit the dynamic content of the signal. Ion signals are dependent on engine conditions including speed, load, boost, air/fuel ratio, fuel additives, and spark plug condition [32]. So the accuracy of the combustion metrics estimation will be affected by the changes of these dependent conditions. Also, as deposit accumulation on the ion probe electrodes will decrease the ion current signal, a self-cleaning mechanism must be considered in its application [32].

Many of the methodologies used to quantify the relationship between the accelerometer signal and the in-cylinder pressure signal show promising results. However, the proposed methods used to model the transfer path, including FRF method and structural identification method, are only applicable for test conditions with limited variations of speed, load, and SOI. Neural network needs large amount of acquired data to train the network. The robustness of the network trained based on single engine is the biggest concern for its application. Also, a majority of the researches were performed on one- or two-cylinder engines which are relatively small in size with low power output.

Current researches for combustion sensing methodologies other than the in-cylinder pressure sensor approach are just confined in laboratory due to their limited effectiveness. High robustness, high efficiency, and good reliability are being pursued for each methodology so that the alternatives of in-cylinder pressure sensor can be used in actual engine management system.

\section{Conflict of Interests}

The authors declare that there is no conflict of interests regarding the publication of this paper.

\section{References}

[1] T. Schnorbus, S. Pischinger, T. Körfer, M. Lamping, D. Tomazic, and M. Tatu, "Diesel combustion control with closed-loop control of the injection strategy," SAE Technical Paper 2008-010651, 2008.

[2] S. Lee, J. Lee, S. Lee et al., "Study on reduction of diesel engine out emission through closed loop control based on the incylinder pressure with EGR model," SAE Technical Paper 201301-0322, SAE International, 2013.

[3] J. Franz, F. Schwarz, M. Guenthner et al., "Closed loop control of an HCCI multi-cylinder engine and corresponding adaptation strategies," SAE Technical Paper 2009-24-0079, SAE, 2009.

[4] J. Yanowitz, R. L. Mccormick, and M. S. Graboski, "In-use emissions from heavy-duty diesel vehicles," Environmental Science \& Technology, vol. 34, no. 5, pp. 729-740, 2000. 
[5] C. Amann, "Cylinder-pressure measurement and its use in engine research," SAE Paper no. 852067, SAE, 1985.

[6] B. K. Powell, G. P. Lawson, and G. Hogh, "Advanced real time powertrain system analysis," ASME Paper no. 87-ICE-46, ASME, 1987.

[7] M. Yoon, K. Lee, M. Sunwoo, and B. Oh, "Cylinder pressure based combustion phasing control of a CRDI diesel engine," SAE Technical Paper 2007-01-0772, 2007.

[8] Z. Yang, R. Stobart, and E. Winward, "Online adjustment of start of injection and fuel rail pressure based on combustion process parameters of diesel engine," SAE Technical Paper 2013-01-0315, SAE, 2013.

[9] Y. Huang, F. Yang, M. Ouyang, L. Chen, and X. Yang, "Optimal feedback control with in-cylinder pressure sensor under engine start conditions," SAE Technical Paper 2011-01-1422, 2011.

[10] F. Taglialatela, M. Lavorgna, E. Mancaruso, and B. M. Vaglieco, "Determination of combustion parameters using engine crankshaft speed," Mechanical Systems and Signal Processing, vol. 38, no. 2, pp. 628-633, 2013.

[11] D. Moro, N. Cavina, and F. Ponti, "In-cylinder pressure reconstruction based on instantaneous engine speed signal," Journal of Engineering for Gas Turbines and Power, vol. 124, no. 1, pp. 220-225, 2002.

[12] F. T. Connolly and A. E. Yagle, "Modeling and identification of the combustion pressure process in internal combustion engines," Mechanical Systems and Signal Processing, vol. 8, no. 1, pp. 1-19, 1994.

[13] Y. Shiao and J. J. Moskwa, "Cylinder pressure and combustion heat release estimation for SI engine diagnostics using nonlinear sliding observers," IEEE Transactions on Control Systems Technology, vol. 3, no. 1, pp. 70-78, 1995.

[14] S. Saraswati and S. Chand, "Reconstruction of cylinder pressure for SI engine using recurrent neural network," Neural Computing and Applications, vol. 19, no. 6, pp. 935-944, 2010.

[15] F. Gu, P. J. Jacob, and A. D. Ball, "A RBF neural network model for cylinder pressure reconstruction in internal combustion engines," in Proceedings of the IEE Colloquium on Modeling and Signal Processing for Fault Diagnosis, Digest no. 1996/260, Leicester, UK, September 1996.

[16] F. Liu, G. A. J. Amaratunga, N. Collings, A. Soliman, and F. Liu, "An experimental study on engine dynamics model based in-cylinder pressure estimation," SAE Paper 2012-01-0896, SAE International, 2012.

[17] T. Dinu, N. A. Henein, and W. Bryzik, "Determination of the gas-pressure torque of a multicylinder engine from measurements of the crankshaft's speed variation," SAE Transactions, vol. 107, no. 3, pp. 294-302, 1998.

[18] G. Rizzoni, "Estimate of indicated torque from crankshaft speed fluctuations: a model for the dynamics of the IC engine," IEEE Transactions on Vehicular Technology, vol. 38, no. 3, pp. 168-179, 1989.

[19] F. Liu, G. Amaratunga, N. Collings, and A. Soliman, "An experimental study on engine dynamics model based in-cylinder pressure estimation," SAE Technical Paper 2012-01-0896, SAE International, 2012.

[20] S. Yoshiyama, E. Tomita, and Y. Hamamoto, "Fundamental study on combustion diagnostics using a spark plug an ion probe," SAE Technical Paper 2000-01-2828, 2000.

[21] M. Hellring and U. Holmberg, "An ion current based peakfinding algorithm for pressure peak position estimation," SAE Technical Paper 2000-01-2829, 2000.
[22] A. A. Martychenko, J. K. Park, Y. S. Ko, A. A. Balin, J. W. Hwang, and J. O. Chae, "A study on the possibility of estimation of in-cylinder pressure by means of measurement of spark gap breakdown voltage," SAE Paper 01-1115, SAE International, 1999.

[23] M. Hellring and U. Holmberg, "An ion current based peakfinding algorithm for pressure peak position estimation," SAE Technical Paper 2000-01-2829, SAE, 2000.

[24] D. Kumar, A. Ramesh, M. K. Gajendra Babu, and P. V. Manivannan, "An ionization current based cylinder gas pressure estimation for knock detection and control in a single cylinder SI engine," Internal Combustion Engines 2009-32-0118, 2009.

[25] S. Yoshiyama, E. Tomita, and Y. Hamamoto, "Fundamental study on combustion diagnostics using a spark plug as ion probe," SAE Transactions, vol. 109, no. 3, pp. 1990-2002, 2000.

[26] R. Johnsson, "Cylinder pressure reconstruction based on complex radial basis function networks from vibration and speed signals," Mechanical Systems and Signal Processing, vol. 20, no. 8, pp. 1923-1940, 2006.

[27] S. Kim and K. Min, "Detection of combustion start in the controlled auto ignition engine by wavelet transform of the engine block vibration signal," Measurement Science and Technology, vol. 19, no. 8, Article ID 085407, 2008.

[28] A. Gazis, D. Panousakis, R. Chen, and W.-H. Chen, "Computationally inexpensive methods of ion current signal manipulation for predicting the characteristics of engine in-cylinder pressure," International Journal of Engine Research, vol. 7, no. 3, pp. 271-282, 2006.

[29] N. M. Danne, D. L. S. Hung, G. G. Zhu, and J. McKoskey, "Knock detection for a large displacement air-cooled V-twin motorcycle engine using in-cylinder ionization signals," SAE Technical Paper 2008-32-0028, 2008.

[30] G. Zhu, D. Hung, and J. Winkelman, "Combustion characteristics detection for low pressure direct injection engine using ionization signal," SAE Technical Paper 2006-01-3317, SAE, 2006.

[31] M. Bellenoue, S. Labuda, S. Julien, A. P. Chernukho, and A. N. Migoun, "Application of ionization probes for diagnostics of knocking combustion," in Proceedings of the 7th Mediterranean Combustion Symposium, Cagliari, Italy, September 2011.

[32] G. G. Zhu, C. F. Daniels, and J. Winkelman, "MBT timing detection and its closed-loop control using in-cylinder ionization signal," SAE Technical Paper 2004-01-2976, SAE, 2004.

[33] J. Naber, J. R. Blough, D. Frankowski, M. Goble, and J. E. Szpytman, "Analysis of combustion knock metrics in sparkignition engines," SAE Technical Paper 2006-01 400, 2006.

[34] F. Guillemin, O. Grondin, J. Chauvin, and E. Nguyen, "Combustion parameters estimation based on knock sensor for control purpose using dedicated signal processing platform," SAE Technical Paper 2008-01-0790, 2008.

[35] L. Arnone, S. Manelli, G. Chiatti, and O. Chiavola, "In-cylinder pressure analysis through accelerometer signal processing for diesel engine combustion optimization," SAE Technical Paper 2009-01-2079, SAE, 2009.

[36] O. Chiavola, G. Chiatti, and E. Recco, "Accelerometer measurements to optimize the injection strategy," SAE Technical Paper 2012-01-1341, SAE International, 2012.

[37] F. Taglialatela, N. Cesario, M. Porto et al., "Use of accelerometers for spark advance control of SI engine," SAE International Journal of Engines, vol. 2, no. 1, pp. 971-981, 2009.

[38] C. J. Polonowski, V. K. Mather, and J. D. Naer, "Accelerometer based sensing of combustion in a high speed HPCR diesel engine," SAE Paper 01-0972, SAE International, 2007. 
[39] C. Polonowski, Accelerometer based measurements of combustion in an automotive turbocharged diesel engine $[\mathrm{PhD}$ dissertation], Michigan Technological University, Houghton, Mich, USA, 2009.

[40] Y. Gao and R. B. Randall, "Reconstruction of diesel engine cylinder pressure using a time domain smoothing technique," Mechanical Systems and Signal Processing, vol. 13, no. 5, pp. 709$722,1999$.

[41] A. J. Morello, J. R. Blough, J. Naber, and L. Jia, "Signal processing parameters for estimation of the diesel engine combustion signature," SAE International Journal of Passenger Cars-Mechanical Systems, vol. 4, no. 2, pp. 1201-1215, 2011.

[42] M. El-Ghamry, J. A. Steel, R. L. Reuben, and T. L. Fog, "Indirect measurement of cylinder pressure from diesel engines using acoustic emission," Mechanical Systems and Signal Processing, vol. 19, no. 4, pp. 751-765, 2005.

[43] J. T. Kim and R. H. Lyon, "Cepstral analysis as a tool for robust processing, deverberation and detection of transients," Mechanical Systems and Signal Processing, vol. 6, no. 1, pp. 1-15, 1992.

[44] R. Villarino and J. F. Böhme, "Fast in-cylinder pressure reconstruction from structure-borne sound using the EM algorithm," in Proceedings of the IEEE International Conference on Accoustics, Speech, and Signal Processing (ICASSP '03), vol. 6, pp. 597600, IEEE, Hong Kong, China, April 2003.

[45] M. Wagner, J. Böhme, and J. Förster, "In-cylinder pressure estimation from structure-borne sound," SAE Technical Paper 2000-01-0930, 2000.

[46] R. Villarino and J. F. Bohme, "Pressure reconstruction and misfire detection from multichannel structure-borne sound," in Proceedings of the IEEE International Conference on Acoustics, Speech, and Signal Processing (ICASSP '04), vol. 2, IEEE, Montreal, Canada, May 2004.

[47] R. Villarino and J. F. Böhme, "Pressure reconstruction and misfire detection from multichannel structure-borne sound," in Proceedings of the IEEE International Conference on Acoustics, Speech, and Signal Processing (ICASSP '04), vol. 2, pp. ii-141-ii144, IEEE, Montreal, Canada, May 2004.

[48] R. Villarino and J. Böhme, "Misfire detection in spark-ignition engines with the EM algorithm," in Proceedings of the 3rd IEEE International Symposium on Signal Processing and Information Technology (ISSPIT '03), pp. 142-145, Darmstadt, Germany, December 2003.

[49] K. Bizon, G. Continillo, E. Mancaruso, and B. M. Vaglieco, "Reconstruction of in-cylinder pressure in a diesel engine from vibration signal using a RBF neural network model," SAE Technical Paper 2011-24-0161, 2011.

[50] L. Jia, J. Naber, J. Blough, and S. A. Zekavat, "Accelerometerbased combustion metrics reconstruction with radial basis function neural network for a 9 $\mathrm{L}$ diesel engine," Journal of Engineering for Gas Turbines and Power, vol. 136, no. 3, Article ID 031507, 2014.

[51] J. M. Desantes and A. J. Torregrosa, "Wavelet transform applied to combustion noise analysis in high-speed DI diesel engines," SAE Technical Paper 2001-01-1545, SAE International, 2001.

[52] A. K. Sen, G. Litak, R. Taccani, and R. Radu, "Wavelet analysis of cycle-to-cycle pressure variations in an internal combustion engine," Chaos, Solitons \& Fractals, vol. 38, no. 3, pp. 886-893, 2008.

[53] A. Hariyanto, K. Bagiasna, I. Asharimurti, A. Wijaya, I. K. Reksowardoyo, and W. Arismunandar, "Application of wavelet analysis to determine the start of combustion of diesel engines," SAE Technical Paper 2007-01-3556, 2007.

[54] J. Borg, G. Saikalis, S. Oho, and K. Cheok, "Knock signal analysis using the discrete wavelet transform," SAE Technical Paper 2006-01-0226, SAE International, 2006.

[55] L. Jia, J. Naber, and J. Blough, "Application of FRF with SISO and MISO model for accelerometer-based in-cylinder pressure reconstruction on a 9-L diesel engine," Proceedings of the Institution of Mechanical Engineers C: Journal of Mechanical Engineering Science, vol. 229, no. 4, pp. 629-643, 2015.

[56] J. B. Heywood, Internal Combustion Engine Fundamentals, McGraw-Hill, New York, NY, USA, 1988. 


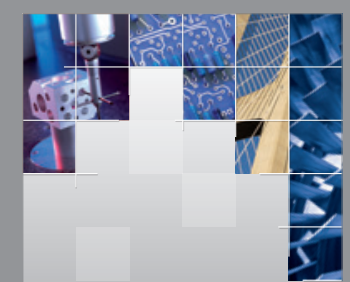

\section{Enfincering}
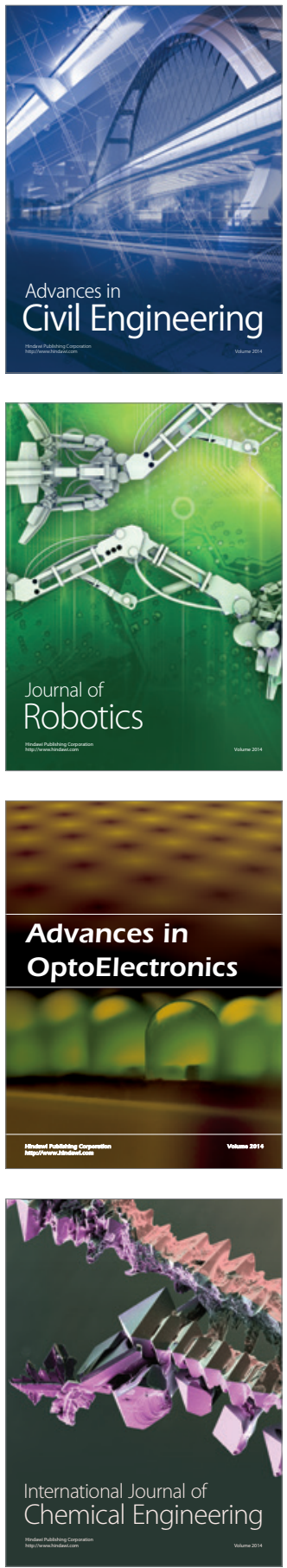

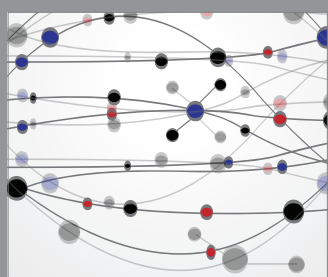

The Scientific World Journal

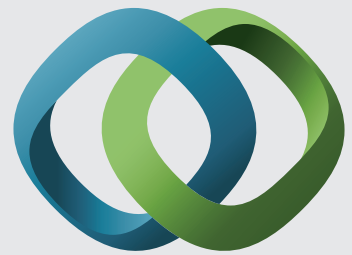

\section{Hindawi}

Submit your manuscripts at

http://www.hindawi.com
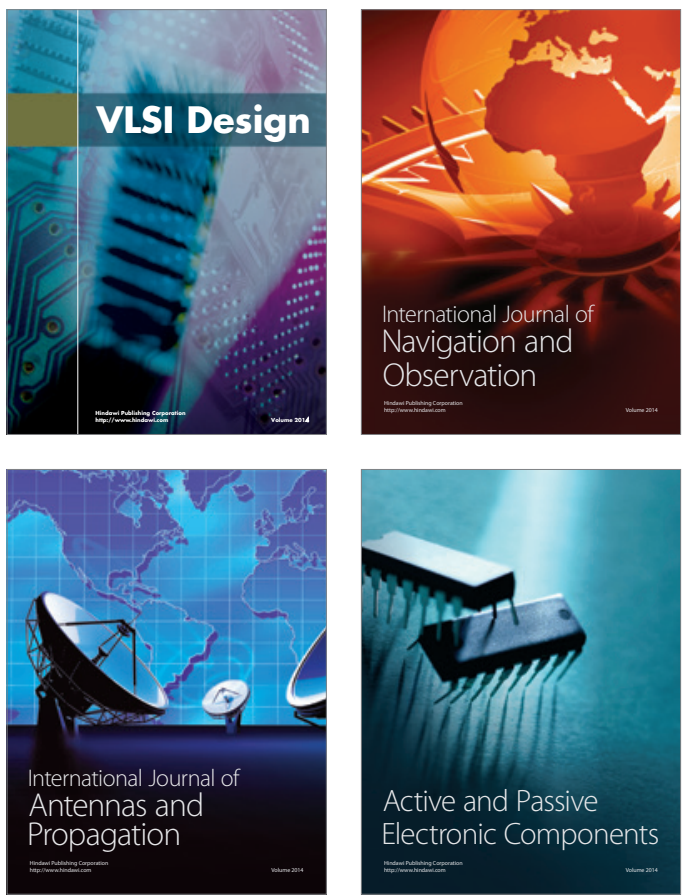
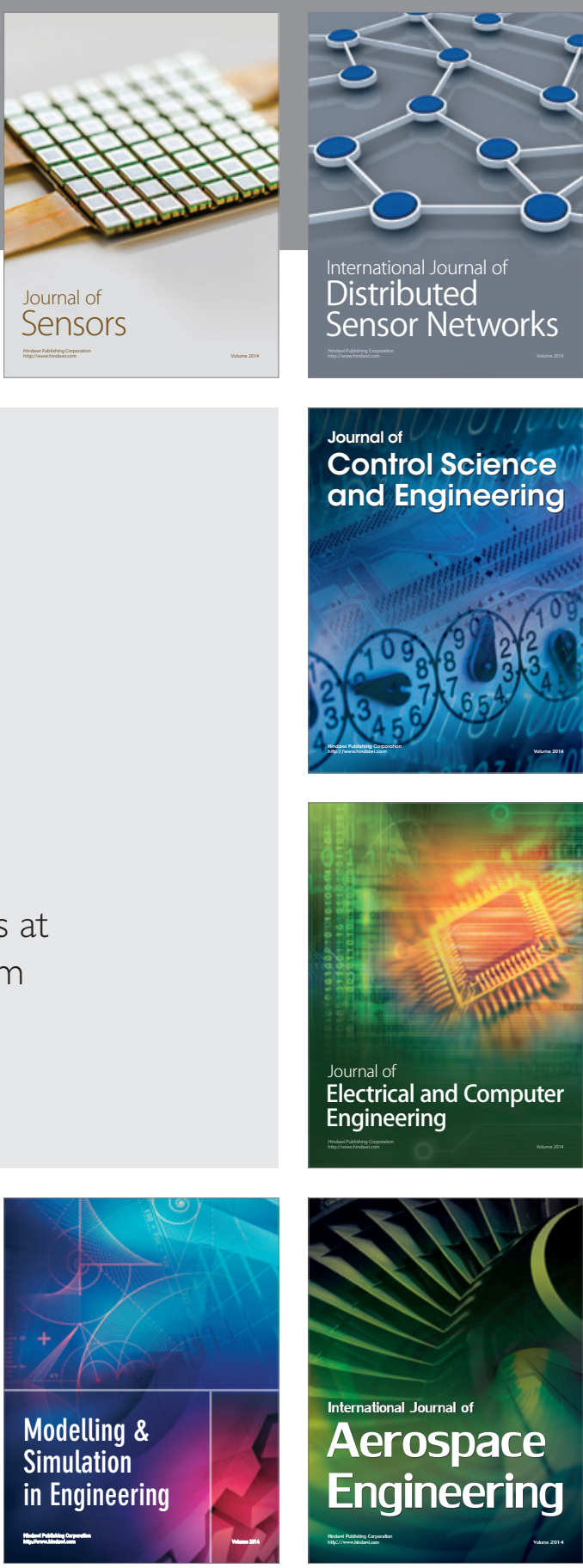

International Journal of

Distributed

Sensor Networks

Journal of

Control Science

and Engineering
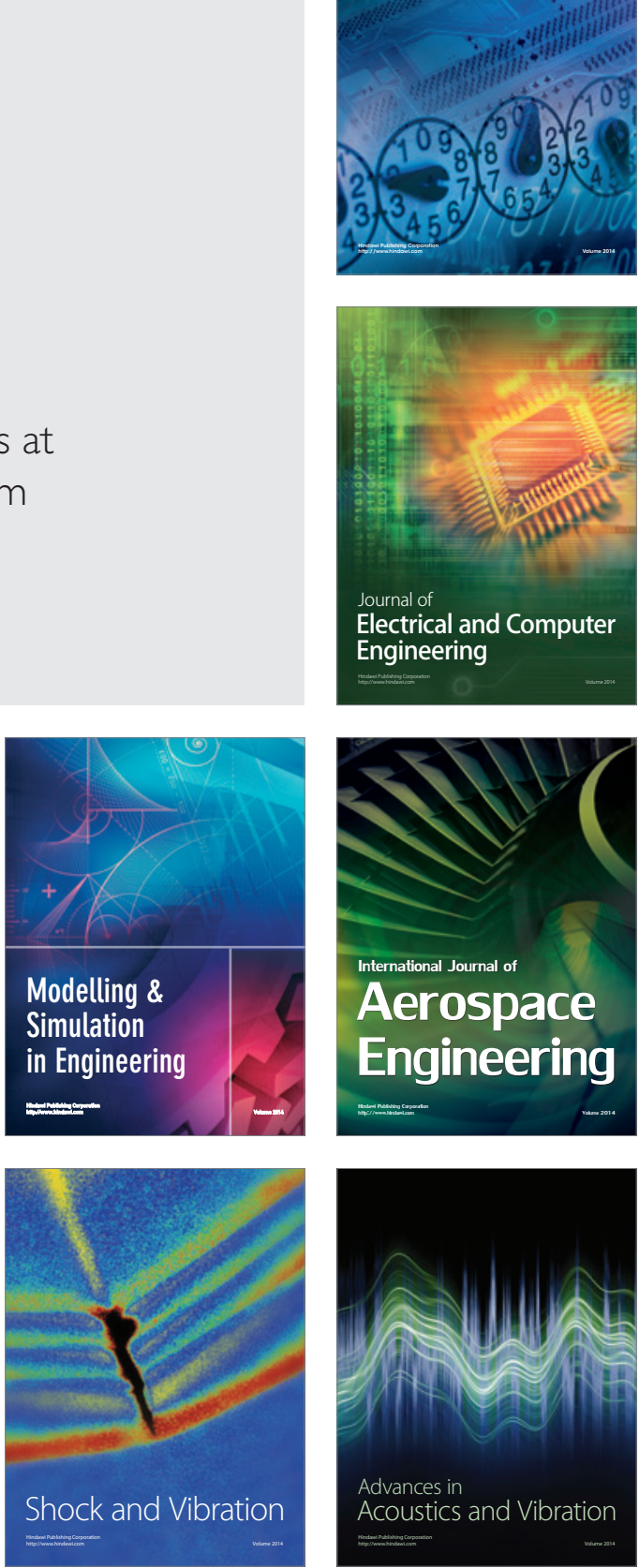